\title{
Revealing a blind spot on the global mental health map: scoping review of 25 years development of mental health care for people with severe mental illnesses in Central and Eastern Europe
}

\section{Authors}

PhDr. Petr Winkler* 1,3; Dzmitry Krupchanka* ${ }^{1,3,4}$ PhD; Tessa Roberts ${ }^{2}$ MSc; Lucie Kondratova ${ }^{1}$ MSc; Vendula Machü ${ }^{1}$; Prof Cyril Höschl ${ }^{1}$ DrSc; Prof Norman Sartorius ${ }^{5}$ PhD; Prof Robert Van Voren ${ }^{6,7,29}$, PhD; Oleg Aizberg ${ }^{8}$ PhD; Prof Istvan Bitter ${ }^{9}$ PhD; Arlinda Cerga-Pashoja ${ }^{2}$ PhD; Azra Deljkovic ${ }^{10}$ MD; Naim Fanaj ${ }^{11} \mathrm{PhD}$, ; Arunas Germanavicius ${ }^{12} \mathrm{PhD}$; Hristo Hinkov ${ }^{13} \mathrm{PhD}$; Aram Hovsepyan ${ }^{14} \mathrm{MD}$; Fuad N. Ismayilov ${ }^{1515}$, 30 DrSc; Prof Sladana Strkalj Ivezic ${ }^{1616,1777}$ DrSc; Marek Jarema ${ }^{1818}$ PhD; Vesna Jordanova ${ }^{1919}$ MD; Selma Kukić ${ }^{20}$; Nino Makhashvili ${ }^{2121}$ PhD; Brigita Novak Šarotar2222, 2323 PhD; Oksana Plevachuk ${ }^{2424}$ PhD; Daria Smirnova ${ }^{2525}$ PhD; Bogdan loan Voinescu ${ }^{2626,2 \underline{27} 27}$ PhD; Jelena Vrublevska ${ }^{2828}$ $\mathrm{MD}$; and Prof Graham Thornicroft PhD ${ }^{3}$

*Both authors contributed equally

\section{Institutions}

1. Department of Social Psychiatry, National Institute of Mental Health, Prague, Czech Republic

2. Department of Population Health, London School of Hygiene and Tropical Medicine, London, UK

3. Health Service and Population Research Department, Institute of Psychiatry, Psychology and Neuroscience, King's College London, London, UK

4. Institute of Global Health, University of Geneva, Geneva, Switzerland

5. Association for the Improvement of Mental Health Programmes, Geneva, Switzerland

6. Ilia State University, Tbilisi, Georgia

7. Vytautas Magnus University, Kaunas, Lithuania

8. Department of Psychiatry and Narcology, Belarusian Medical Academy of Postgraduate Education, Minsk, Belarus

9. Department of Psychiatry and Psychotherapy, Semmelweis University, Budapest, Hungary

10. Mental Health Center, Health Care Center Pljevlja, Plevlja, Montenegro

11. Mental Health Center, Prizren, Kosovo

12. Clinic of Psychiatry, Faculty of Medicine, Vilnius University, Vilnius, Lithuania

13. National Center for Public Health and Analyses, Sofia, Bulgaria

14. Department of Psychiatry, Yerevan State Medical University, Yerevan, Armenia

15. Department of Psychiatry, National Mental Health Centre, Azerbaijan Medical University, Baku, Azerbaijan

16. Croatian medical association, Zagreb, Croatia

17. Croatian society for clinical psychiatry, Zagreb, Croatia

18. 3rd Department of Psychiatry, Institute of Psychiatry and Neurology, Warszawa, Poland

19. Department of Psychological Medicine, Institute of Psychiatry, Psychology and Neuroscience, Kings College London, London, UK 
20. Mental Health Project in Bosnia and Herzegovina, Sarajevo, Bosnia and Herzegovina

21. Mental Health Resource Centre, Ilia State University, Tbilisi,Georgia

22. University Psychiatric Clinic Ljubljana, Ljubljana, Slovenia

23. Department of Psychiatry, Faculty of Medicine, University of Ljubljana, LjubljanaSlovenia

24. Department of psychiatry, psychology and sexology, Danylo Halytsky Lviv National Medical University, Lviv, Ukraine

25. Department of Psychiatry, Narcology, Psychotherapy and Clinical Psychology, Samara State Medical University, Samara, Russia

26. Department of Clinical Psychology and Psychotherapy, Babes-Bolyai University, Cluj-Napoca, Romania

27. Department of Forensic and Neurodevelopmental Science, King's College London, London, UK

28. Department of Psychiatry and Narcology, Riga Stradins University, Riga, Latvia

29. Human Rights in Mental Heath - FGIP, Hilversum, The Netherlands

30. National Mental Health Centre, Baku, Azerbaijan

31. Foundation Global Initiative on Psychiatry-Tbilisi, Tbilisi, Georgia

\section{Corresponding author}

Petr Winkler; Tel: +420 728221 883; Email: petr.winkler@nudz.cz, petr.winkler@kcl.ac.uk;

Correspondence address: Department of Social Psychiatry, National Institute of Mental Health, Topolová 748, 25067 Klecany, Czech Republic. 


\section{Abstract}

Twenty-five years have passed since the major socio-political changes in Central and Eastern Europe and our aim was to map and analyze the development of mental health care practice for people with severe mental illnesses in this region since then. A scoping review was complemented by an expert survey in 24 countries. Mental health care practice in the region differs greatly across as well as within individual countries. National policies often exist but reforms remain mostly in the realm of aspiration. Services are predominantly based in psychiatric hospitals. Decision making on resource allocation is non-transparent, and full economic evaluations of complex interventions and rigorous epidemiological studies are lacking. Stigma seems to be high compared to other European countries, but consideration of human rights and user involvement are increasing. The region has seen respectable development, which occurred due to grassroots initiatives supported by international organizations, rather than due to systematic implementation of government policies.

(150 words, unstructured)

Funding: This study had no specific funding.

\section{Key words}

Mental health; psychiatry; Central and Eastern Europe; scoping review 


\section{Introduction}

The year 2016 marked a quarter of a century since the dissolution of the Soviet Union, which was the symbolic end of communist rule in Central and East Europe (CEE). CEE, as defined by the United Nation's Eastern European Group ${ }^{1}$, encompasses 24 countries (including Kosovo) and approximately 342 million people ${ }^{2}$. For the majority of the twentieth century, mental health systems in CEE developed under the influence of communist and socialist ideologies.

This ideological influence differed across the region, however. Whereas the countries of the former Soviet Union were fully dominated by the Moscow School of Psychiatry and had limited contact with the international community, the countries of Southeast and Central Europe were more open to the outside world, and in some there were even examples of community-based care models (for instance in former Yugoslavia) $)^{3,4}$. Despite the heterogeneity, CEE mental health systems shared many similar characteristics. People with severe mental illnesses were almost exclusively treated in large psychiatric hospitals ${ }^{4}$; mental health care systems were organized and funded centrally by the government; many branches of psychiatry-related social science, such as social psychiatry, psychiatric epidemiology, service research, and mental health economics were largely underdeveloped ${ }^{4}$; decision making in general was the subject of ideological rather than scientific scrutiny; and neither staff, patients and their families, nor citizens were considered as stakeholders. ${ }^{5}$ The profound socioeconomic transformations that occurred in 1989-1991, theoretically, enabled individual countries to start addressing gaps in mental health care without the previous ideological constraints.

Since then, numerous political initiatives have emerged with the aim to improve care for people with mental illnesses. These have been largely in line with the principles enshrined by the Universal Declaration of Human Rights ${ }^{6}$ and Alma Ata Declaration ${ }^{7}$; and included the UN Principles for the Protection of Persons with Mental Illness ${ }^{8}$ and later the Convention on the Rights of Persons with Disabilities ${ }^{9}$, as well as documents by the European Regional Office of the World Health Organization (WHO) such as the Mental Health Declaration and the Mental Health Action Plan for Europe ${ }^{10,11}$.

However, unfavourable news about mental health care in CEE has continued to emerge. It has been stated that mental health care reforms, so often announced in the region, remain largely unimplemented ${ }^{4,12}$. The burden of mental and substance use disorders in CEE has been identified as one of the greatest in the world ${ }^{13}$, the prevalence of PTSD and other mental health problems seems to be considerably elevated in countries that have experienced recent conflict ${ }^{14}$, suicide rates are medium to high, ${ }^{15}$ and the level of alcohol consumption is excessive. ${ }^{16}$ Despite some success in deinstitutionalization and changes in legislation, ${ }^{17}$ there is evidence of excessively long or unacceptably short hospitalizations ${ }^{18}$ and otherwise inadequate services, ${ }^{19}$ as well as reports of the abuse of psychiatry ${ }^{20}$ and human rights violations in some countries ${ }^{19,21-23}$. The allocation of financial resources for mental health care is reported to be far below the EU average of European Union $(E U)^{24}$ and the vast majority of resources are still spent on outdated institutional systems ${ }^{25}$. The lack of nonbiological or non-clinical research in general has been considered widespread, with CEE countries having the lowest publication rate per capita in Europe in both public mental health ${ }^{26}$ and stigmarelated ${ }^{27}$ research. However, the abovementioned evidence is fragmented, and no systematic mapping of development of mental health practices with relation to people with severe mental illnesses has been conducted in the region as a whole.

The aim of this study was to summarise and analyse evidence about the last 25 years of development and the current state of mental health care practice in the countries of CEE. In doing so, the authors 
intend to help fill an important blind spot on the Global Mental Health map and shed light on future priorities for the region.

\section{Methods}

We considered the countries of CEE in terms of four sub-regions: I. The East European Countries of the former Soviet Union (Belarus, Russian Federation, Ukraine, Armenia, Azerbaijan, Georgia), II. The Baltic Countries of the former Soviet Union (Latvia, Lithuania, Estonia), III. The Central European countries of the former Eastern Bloc (Czech Republic, Hungary, Poland, Slovakia), and IV. The Southeast European countries (Albania, Bulgaria, Romania, Moldova, Bosnia and Herzegovina, Croatia, Kosovo, Macedonia, Montenegro, Serbia, Slovenia).

We were interested in assessing developments in mental health practice in the CEE region in the last 25 years. This overarching aim was split into more focused objectives addressing each of the topics of interest (see below). Given the broad scope of this enquiry, published guidance on scoping reviews was followed ${ }^{28-31}$. This involved employing a broad search strategy to identify relevant studies; selecting studies according to inclusion and exclusion criteria; charting the data; collating, summarizing, and reporting the results; and conducting consultations with relevant experts in the field. We placed particular emphasis on the last component and supplemented the review with a comprehensive survey of a purposive sample of experts. This survey was an essential part of the review and therefore this information was integrated in the data charting stage. In line with the aims of the review, results are presented by theme to show mental health care practices across the region (operationalized below). 


\section{Search strategy}

Medline, Psyclnfo, Embase, Web of Science and the Cochrane Library were searched using combinations of terms referring to the region and the mental health topics specified below (full strategy in Appendix 1). Results were retrieved on the 8th August 2016. There were no restrictions on language, but the search was limited to documents published from 1989 onwards. Much attention was also dedicated to local scientific journals and grey literature searches as it has been pointed out that research from CEE is under-represented in international peer-reviewed journals. ${ }^{32}$ Co-authors were instructed to use the advanced search feature in Google Scholar and to provide useful references that were not identified through our search strategy. Reports, chapters, books, theses, letters, and media reports were all eligible for inclusion into our final analysis. A total of eighty additional papers were found in this manner.

After removing duplicates, the title and abstracts of all references retrieved were screened by the review team. We piloted the inclusion/exclusion criteria individually (PW, DK, TR, LK) and then discussed discrepancies as a team, to ensure a high level of agreement.

Subsequently DK and TR screened studies by authors with names beginning A-K, while PW and LK screened those by authors with names starting L-Z. Inter-rater reliability was calculated simply as percentage of agreement (i.e. number of studies that both authors agreed on / total number of studies). Disagreements were in the first instance resolved through discussion between the two researchers screening the same articles, and in the second instance through discussion among all four researchers.

The review was initially conducted in English (PW, DK, TR, LK) and later enhanced by grey literature searches in other regional languages (conducted by the regional collaborators in Russian, Ukrainian, Latvian, Lithuanian, Belarusian, Czech, Polish, Serbian, Georgian, Armenian, Croatian, Albanian, Macedonian, Slovenian and Bulgarian). We supplemented the search strategy with hand searching to ensure that all relevant research and reports were included.

The focus of this review was on the last 25 years of development and current practice of mental health care for people with severe mental illnesses (SMI). Severe mental illness was defined as an ICD-10 diagnosis of an affective disorder or non-affective functional psychotic disorder [F20-F22, F24, $F 25, F 28-F 31, F 32.3$, and F33.3]. This is in accord with standard definitions of SMI, although studies often apply additional criterions of illness duration and disability. ${ }^{33}$ Severe mental illnesses were selected for feasibility reasons and due to their high socio-economic burden ${ }^{34}$. Articles on child and adolescent psychiatry, geriatric psychiatry, learning disability psychiatry and addiction psychiatry were excluded, as were forensic psychiatry papers unless these addressed human rights violations of people with SMI.

We operationalized "mental health care practice" as follows: A system of mental health services that are provided by specifically educated professionals and influenced by policy, resources and legislation. 
Policy decisions can be informed by data about the epidemiology of SMI, economic evaluations, and service user and family involvement, or they can be uninformed. Violations of service users' human rights, when occurring within health and community services, suggest failures in mental health care practices. Levels of public stigma indicate societal willingness to accept people with SMI as members of the community, which is likely to influence policy, funding, recovery, help-seeking behavior, service quality, and quality of life for people with SMI.

We therefore included articles focused on: (1) mental health services (inpatient, outpatient, primary care, community and residential services for people with SMI); (2) epidemiological studies of population mental health; (3) policy and legislation; (4) user and family members' involvement in service delivery and planning; (5) resource availability/allocation, and economic evaluations of complex interventions; (6) quality/duration of training for mental health specialists (including the availability of education for mental health care development, such as health service research, psychiatric epidemiology, mental health economics); and (7) studies on mental health-related stigma amongst the general population and amongst current or future health care professionals. In all cases we were interested in assessing both the current state of affairs and changes that have occurred since 1989-1991, up to August 2016.

Our main interest was in primary studies, including all qualitative and quantitative designs. However, we also considered opinion papers, editorials, and reports, as we expected to find a shortage of evidence. We excluded conference abstracts, and case studies of individual patients, programs or facilities, as we assumed that we could not reasonably generalize their messages. Clinically-, biologically-, etiologically- or psychometrically-oriented research was also excluded. We included economic evaluations of complex interventions (as opposed to pharmaco-economics only) and cost of illness studies since these are important for informing decisions on resource allocation, and therefore are relevant to rational planning of mental health services. Studies that were concerned with specific events, such as the war in former Yugoslavia or the earthquake in Armenia, were considered only if they contributed to the understanding of mental health practice development in the above-mentioned fields. Detailed inclusion and exclusion criteria are presented in Appendix 2.

--- Appendix 2 about here ---

\section{Expert survey}

To triangulate the findings from the literature review, and to address the anticipated lack of literature, ${ }^{26,27}$ the review was complemented by an expert survey. Expert reports were collected by country collaborators (OA, IB, ACP, AD, NF, AG, HH, AH, FNI, SSI, MJ, VJ, SK, NM, BNS, OP, DS, BIV, EV) who approached up to five experts in their countries. For the Czech Republic and Slovakia this was done by PW. We were unable to find collaborators in Estonia, Moldova or Serbia.

"Experts" were considered to be persons involved in the organization and/or provision of mental health care, or affected by services, including members of local professional associations; members of local service user and family organizations; World Psychiatric Association representatives and mental health-related WHO representatives. Country collaborators decided on the final list of experts based on their understanding of the local situation. The expert survey attempted to maintain a balance between three factors: diversity of views; taking key stakeholders' opinions into account; and feasibility of data collection. Reports were collected using a pre-developed "Expert Report Form" 
(see Appendix 3) and focused on the same topics as the literature review. Experts' reports have not been peer-reviewed and should be interpreted as qualitative data sources rather than established facts.

\section{Charting the data}

A data charting form was developed to classify the identified literature according to the abovementioned topics, and by whether studies were published in an internationally recognized journal. Internationally recognized journals were operationalized as those which have received an impact factor, although some of these are published in local languages, such as Psychiatria Polska. The following data were extracted into the form: full reference, including abstract; thematic focus of the paper; and study location. Data extraction was conducted in the same way as reference screening, i.e. data from studies by authors' names starting A-K were extracted by DK and TR, and from L-Z by PW and LK. The final chart presented in Appendix 4 was then composed by PW.D

Data from the Expert Report Forms were charted using the same structure described above. The coding of expert reports was conducted independently by two researchers (DK, LK) who familiarized themselves with the reports, highlighted data relevant to each sub-topic and extracted information to create individual country summaries (Appendix 5). In case of conflicting opinions among country experts, both perspectives were included in the respective country's profile.

\section{Collating, summarizing, and reporting results}

We attempted to collect evidence for each country of the region and on each of the topics.

Framework analysis ${ }^{35}$ was used to synthesize the results, including expert reports, to address each of the themes listed above. Microsoft Excel was used to conduct the framework analysis. With regard to the literature, we used the saturation approach, starting with examining evidence that was published in internationally recognized journals.

Saturation was reached when the following questions were answered for each country, with regard to both developments over the last 25 years and the current situation:

i) Has the number of beds in psychiatric hospitals changed?

ii) Is the mental health care system still reliant on large psychiatric hospitals?

iii) Do plans for community care development exist, and to what extent have they been implemented?

iv) Do any examples of high-quality community services exist?

v) Have there been changes in legislation regarding the rights and care of patients with severe mental illness?

vi) Do human rights violations still occur? What has been done to improve the situation?

vii) Have any studies of stigma been conducted? Is stigma being reported as a considerable issue for mental health practice?

viii) Have any full economic evaluations of complex interventions been conducted?

ix) Have any population-based epidemiological studies been conducted?

Once each question had been answered for each country, abstracts for the remaining papers on this topic were checked for agreement with the answers generated so far. If the findings were consistent then it was not necessary to use the additional papers. 
Data from sub-topic summaries based on expert reports were summarized within the overall description of the country, to create country profiles based on both the literature and expert survey (Appendix 5). For topics related to mental health resources, education of mental health professionals, human rights and user involvement, country profiles relied on the expert reports as the primary data source, due to a substantial literature gap on these topics (see Table 1). We then used narrative summary to provide an account of the evidence on development of mental health care practices in the region over the last 25 years.

\section{Consultations and interpretation of the findings}

At the last stage of the review, co-authors from each of the participating countries were asked to check the accuracy and currency of the information on their country, and assist with overall interpretation within the manuscript. Findings are reported in the context of the overarching aims of the study, including discussing implications for future research, practice and policy. Given the wide range of study designs included in the study, detailed quality assessment criteria could not be applied, which is standard in scoping reviews. ${ }^{30}$

\section{Results}

Our search strategy resulted in a total of 24,852 and 12,785 references, before and after removing duplications respectively. Inter-rater reliability was calculated at $97.4 \%$, indicating a high level of agreement. We examined 464 full texts, and found 8 articles not meeting our inclusion criteria. We used 183 articles to compose country reports for each country in the region (see flowchart below, and Appendix 5 for country reports).

--- Figure 1 about here ---

For each topic, a descriptive numerical summary of the studies from each country is presented, showing the scope of the research found (Table 1). The equivalent table with full citations is presented in Appendix 4. As shown in Table 1, 458 articles meeting inclusion criteria were found. Most of these articles ( $n=236$ ) fell into the category entitled "Services: structure, development and reforms". An additional 52 articles focused on policy or legislation, 24 on education or human resources, 21 on financial resources, 18 on human rights and 7 on user involvement. Our search strategy identified only 37 epidemiological articles reporting on the prevalence or incidence of SMI in either the general or the treated population; 50 articles reporting levels of stigmatizing attitudes and/or discrimination among the public, health care professionals, or self-stigma among patients and/or family members; and 13 economic evaluations. Only 187 out of the total 458 articles were published in journals with an impact factor. The remaining articles were published in local journals, or were reports from organizations such as the WHO.

Expert reports were collected for all countries except three (Estonia, Moldova, Serbia). Overall 62 expert reports were collected from 21 countries: Albania (1); Armenia (3); Azerbaijan (3); Belarus (3); Bosnia and Hercegovina (5); Bulgaria (3); Croatia (5); Czech Republic (3); Georgia (5); Hungary (3); 
Kosovo (4); Latvia (2); Lithuania (1); Macedonia (4); Montenegro (1); Poland (1); Romania (1); Russia (4); Slovakia (1); Slovenia (4); Ukraine (4). The majority of experts were representatives of local professional associations and held leading positions in academia and/or service provision. There were also some reports from representatives of local service user and family organizations, although not for every country.

Individual country profiles, summarizing results from the literature synthesis and expert survey, are presented in Appendix 5. Hereinafter the presentation of the results is limited to the synthesis of findings from across countries.

--- Table 1 about here ---

\section{Synthesis}

\section{Mental health care development}

Between 1991 and 2016, the region witnessed substantial shifts in its approach to mental health services. The monopoly of the medical model of mental disorders weakened and attention to the social aspects of mental health care practice increased across the region. However, countries differ considerably in terms of how successful they have been in reforming their mental health care systems.

Development in some regions has been temporarily disrupted by catastrophes, such as the wars and civil unrest in former Yugoslavia, Albania, Armenia, Azerbaijan, Georgia, and Ukraine, as well as natural disasters such as the earthquake in Armenia. This has often brought about specific catastrophe-related needs, such as high rates of PTSD, but also severe damage to the hospital-based mental health care systems in the affected countries.

The number of psychiatric beds in the region has decreased significantly in all CEE countries over the last 25 years. However, this has rarely been accompanied by adequate development of community services and institutionalization continues to occur. With only a few rare exceptions, mental health care across the region remains centralized and based around psychiatric hospitals. Psychiatric hospitals are often reported to be in an inadequate condition, and in practice these often substitute community and housing services.

Systems of outpatient psychiatric care, which were already relatively well developed during the Communist period, continue to function. However, it has been pointed out that this care is often limited to the prescription of medications and that its integration and cooperation with other sectors of both mental and general health care is problematic.

In some countries, networks of community care are well developed and integrated into the mental health system. In Bosnia \& Herzegovina and Kosovo this was a consequence of the destruction of inpatient care systems during the war, and the subsequent development of community mental health care in the aftermath, which was managed and partly financed by the UN. Examples of excellent community projects, facilities and services exist all over the region, although countries differ in the proportion of their affected populations that have access to these services. Cases of highly developed community services are certainly not limited to the region's higher-income 
countries. However, these high quality services have often been developed through the enthusiasm of individual people and organizations, and were strongly supported by international bodies (e.g. the Swiss, Dutch and Swedish funds, the WHO, and the Open Society Fund) rather than through national governments. These projects often have problems with sustainability, scaling up, and integration into mainstream mental health care systems, especially in terms of statutory funding.

The developments described in mental health care practice over the past 25 years do not seem to have been uniformly favorable across all countries. Experts from Bulgaria, for instance, reported that the system has deteriorated. Therapeutic farms - a form of agriculturally-oriented occupational therapy attached to psychiatric hospitals that existed before 1990 - were abolished completely, and the system as a whole has been affected by frequent and chaotic changes in policies and financing, which are characterized by a general lack of interest in mental health care and underfunding.

\section{Policies and legislation}

The vast majority of countries in the region have developed and approved a specific mental health policy. Integral to these newly developed policies are the intentions to develop community mental health care, to decrease stigmatization, and to improve conditions in inpatient facilities. However, these policies remain largely unimplemented, and changes have been more cosmetic than structural. The same applies to legislation, which has been improved across the region, but is reportedly rarely enforced in practice.

\section{Resources and informed decision making}

All countries in the region are reported to have unjustifiably under-financed mental health systems. Although exact numbers are unavailable, and community services are considered to be social services and are therefore often financed from other sources, the proportion of health care budgets allocated to mental health is estimated to be around 3\% (equivalent to US\$18.7 USD per capita) in most CEE countries ${ }^{24}$. This is far below the average in EU countries that were not part of the former Eastern Bloc, where the respective proportion is 7\% (equivalent to \$293.7 USD per capita). ${ }^{24}$

We also found very little information with regard to economic evaluations and only one full economic evaluation comparing the costs and outcomes of two complex interventions. This evaluation built upon WHO-CHOICE methodology ${ }^{36}$ and estimated the costs and outcomes of a hypothetical situation in Estonia; in other words, it did not evaluate any intervention that took place in practice. Epidemiological studies on the prevalence of SMI are also rare, and those that exist are often insufficiently rigorous to be published in internationally recognized journals. Therefore, it is not clear on what basis resources allocation decisions are made, and there is a high risk of countries' already limited mental health budgets being spent ineffectively.

This also applies to human resources, which should be allocated according to the best available evidence to make the most effective use of those specialists that exist. Nowadays, a considerable proportion of mental health professionals are working in hospital settings. Although education for psychiatrists and other mental health professionals has improved considerably, interest amongst medical students is low, and those who obtain high quality education often migrate to countries with higher incomes and a longer history of democratic rule. 
Self-help groups and service user organizations for people with SMI exist almost in all countries of CEE. However, service users' involvement in mental health care development continues to be rare across the region. The voices of service users and their families, despite being increasingly raised, at present seem not to have gained sufficient strength to overcome the structural discrimination and huge disparities between mental and general health care. People with SMI are also reported to face poverty and economic exclusion.

Examples of human rights violations have been reported across the region, although the level, character and frequency of violations differs between countries. This situation is changing for the better. Ombudsman institutions (public defenders of rights) have been introduced in many countries, legislation has been amended for patients' benefit, and service user associations have become more active.

There seem to be many anti-stigma activities mentioned across the region, but these rarely include thorough evaluation and therefore are not reported to the scientific community. Those which are part of larger international projects (e.g. the WPA's Open the Doors Program) are exceptions in this regard. There are indications that levels of stigma among both the public and health care professionals are alarmingly high, but empirical evidence is limited to very few studies. The same seems to apply to stigma among family members, even though families bear a substantial part of the disease burden and provide care to a large proportion of people with SMI. The evidence in this regard, however, is almost exclusively anecdotal.

\section{Discussion}

Over the last 25 years, Central and Eastern European countries experienced socio-political and economic transformation. Mental health care has evolved in the context of significant societal changes, including centralized economies being displaced by market-oriented economies, and health insurance replacing state-funded health care.

In some countries, the International Classification of Diseases was newly introduced. The ideological shift in understanding mental health and healthcare has also been profound ${ }^{37}$. During Soviet times, psychiatry was strongly biologically oriented and mental health problems were considered to have a purely biological basis ${ }^{38,39,9}$. On the other hand, social problems, including those related to SMI, were regarded as the leftovers of capitalism. The majority of the social science disciplines were considered 'bourgeois quasi-sciences', and were de facto prohibited ${ }^{39}$. The absence of social science in psychiatry has not yet been overcome, which is apparent when considering the lack of research on these topics identified by the current review. This lack of evidence might be a major factor behind the non-transparent decision making so often reported in the region, because in the absence of evidence, discussions are driven exclusively by stakeholders' opinions and interests.

In terms of mental health services, the 25 year period after 1989-1991 has seen some positive developments in community and social psychiatry, in which recovery is promoted and enhanced via the establishment of community service networks that are well integrated into the mental health care system. This route has been difficult, however, and countries have had to deal with many adverse phenomena that occurred after the collapse of communism. These included, for instance, unemployment and increased homelessness, but also anomia - a state in which old societal values 
are no longer valid and new ones have yet to be established. ${ }^{40}$ Additionally, there were social crises, human and natural catastrophes which all affected population health as well as health care systems. Unfortunately, people with SMI often bore the consequences of these crises most severely - they were among the first to lose their jobs in the economic transition, and the most affected by national budget cuts. ${ }^{41}$

At present, good quality community services are available to only a fraction of those who need them in the region. The infrastructure that exists, besides psychiatric hospitals and outpatient care which are largely limited to providing shelter and medications, can be largely attributed to the enormous efforts of enthusiastic individuals and organizations, rather than due to strategic development and political dedication on the part of governments.

At the same time, support from the international community has been tremendous during this period. The Open Society Foundation, Geneva Initiative, Netherlands, Switzerland, Sweden and the WHO have helped to establish some high quality community services for people with SMI. However, the sustainability of projects supported via external sources cannot be taken for granted. For instance, financial support has shrunk for many countries as their economies have grown and they have joined the EU. The EU provides new opportunities and resources, financially as well as in terms of expertise, though these are often not utilized and are not available to countries outside the Union.

"The problem is, however, that in absence of a political will to invest in the infrastructure of mental health promotion and a new type of community based services, the same priorities as in Soviet times will continue to be funded: psychiatric hospitals, long term care institutions for mentally ill and mentally retarded persons, and biomedical therapies" ${ }^{42}$. This statement, written by the Lithuanian psychiatrist Dainius Puras which, could be conclusion of the current review if it was not written almost 20 years ago.

\section{Strengths and limitations}

A broad literature search strategy and extensive expert survey were utilized to obtain information on the development of mental health care practice in the region during the last 25 years. Findings from the literature were systematically collected and triangulated with information from local experts, thereby increasing this review's reliability.

However, this study has a number of limitations. First, the operationalization of 'mental health care practice' utilized may be considered overly narrow, i.e. focused only on people with SMI and excluding child and adolescent, old age, and substance-related disorders. Neither the domains of prevention and promotion, nor forensic psychiatry, were included. Furthermore, it was not possible to review studies related to medicine in general, some of which could convey information relevant to psychiatry, such as general health policy or medical corruption.

Another limitation relates to the search strategy, which was not specifically tailored to capture each of the specific sub-topics of interest in depth, such as stigma and human rights violations. It is likely that some articles on these topics were excluded, presumably those published in journals of lower quality and those which were not clearly indexed within the scientific databases. This review, therefore, should not be considered as a comprehensive review of all mental health related stigma and human rights reports in the CEE region, but rather as an attempt to gain insight into the level of research conducted on stigma in the region. 
A further limitation is that we were not able to provide exact quantitative data on phenomena such as numbers of psychiatric beds closed, percentage of health budgets dedicated to mental health, numbers of psychiatric nurses employed, levels of public stigma etc. Although such information may appear to be available in international databases, these are highly unreliable ${ }^{24}$, and additional rigorous studies are needed to obtain high quality data.

Yet another limitation relates to the definition of internationally recognized journals as those with an impact factor. We are aware of the limitations associated with applying this as a criterion of international recognition. However, we opted for this metric for the sake of transparency in the presentation and interpretation of results. While the review of papers published in journals with an impact factor may be considered exhaustive, the list of papers published in journals with no impact factor should be regarded with caution, as many of local journals are not listed in scientific databases or even available online. We cannot rule out the possibility that some potentially relevant papers might have been missed from these sources.

Additionally, we were not able to obtain full texts of 191 articles that might have potentially conveyed useful information. It is also possible that some important information was contained in the articles that we were not able to retrieve.

Finally, there is the potential for bias related to data collection. Some experts were more diligent than others in conducting grey literature searches in their own languages, and we have not incorporated their grey literature search into the results of our systematic search. Some expert reports may therefore be more objective than others. The same applies to assessing the scope of local literature that may have been missed by our systematic search strategy. Information obtained from experts could be further biased by a number of factors, such as experts themselves being providers of specific services or fear of criticism where this may impact on their career prospects.

Despite the aforementioned limitations, we believe that overall the combination of methods used provided some safeguards against unreliable information, allowing us to obtain a reasonably balanced view of mental health care practices in CEE. We also hope that this review will also serve as a stimulus for other experts to provide further evidence that will enhance our understanding of this important topic.

\section{Conclusions}

This is the largest review on mental health systems in the former Eastern Bloc ever conducted. It largely confirms the findings of previous reviews and reports, such as that published by Samele et al. $(2013)^{43}$. However, it adds to these by regarding the region as a whole, as opposed to selected countries only, and it reflects on changes over 25 years of development. The greatest challenges seem to be insufficient resource allocation and non-transparent decision making.

In our opinion, recent successes in bringing mental health onto the global development agenda provide an exceptional opportunity to advance mental health systems in CEE. The explicit incorporation of mental health into the UN Sustainable Development Goals (targets 3.4 and 3.5) ) $^{44}$, as well as the World Bank-WHO Meetings 13-14 ${ }^{\text {th }}$ April 2016: "Out of the Shadows: Making Mental Health a Global Priority" 45 , and other initiatives, have brought mental disorders from the periphery to the center of global attention. The World Health Organization's mh-GAP program ${ }^{46}$ and comprehensive Mental Health Action Plan 2013-2020 47,48 provide high quality frameworks for 
reforms, to which CEE countries are committed. The Global Mental Health movement may be utilized as a vehicle for continual implementation of the necessary improvements in mental health care.

Capacity building to promote excellence in research should be strengthened in order to accelerate the production of high quality evidence, and user and family organizations should be supported to participate in policy making and service planning, and to promote recovery-oriented development in mental health care practice across the region. 


\section{Acknowledgements}

Petr Winkler, Dzmitry Krupchanka, Lucie Kondrátová, Vendula Machů and Cyril Höschl are supported by the project Nr. LO1611 with a financial support from the Ministry of Education Youth and Sport under the NPU I program.

Graham Thornicroft is supported by the National Institute for Health Research (NIHR) Collaboration for Leadership in Applied Health Research and Care South London at King's College London Foundation Trust. The views expressed are those of the author(s) and not necessarily those of the NHS, the NIHR or the Department of Health. GT acknowledges financial support from the Department of Health via the National Institute for Health Research (NIHR) Biomedical Research Centre and Dementia Unit awarded to South London and Maudsley NHS Foundation Trust in partnership with King's College London and King's College Hospital NHS Foundation Trust. GT is supported by the EU Seventh Framework Programme (FP7/2007-2013) Emerald project.

We are indebted to the many people who kindly shared their invaluable insights with regard to the countries in which they work, without whom this project would not have been possible. Our gratitude is extended to all those who offered their time and knowledge to participate in the study. Albania: Gentiana Qirjako; Armenia: Armen Soghoyan, Khachatur Gasparyan; Azerbaijan: Polad Azizov, Gulay Mammadzada; Belarus: Roman Evsegneev, Daria Yeskevich, Nina Kruk; Bosnia and Herzegovina: Visnja Banjac, Dalibor Jozičić, Darko Višić, Elma Hadžić, Goran Cerkez; Bulgaria: Mariya Petrova, Georgi Hranov; Croatia: Miro Jakovljevic, Vlado Jukic, Aleksandar Savic, Martina Rojnic Kuzman; Czech Republic: Pavel, Mohr, Pavel Říčan, Dana Chrtková; Georgia: Eka Chkonia, Giorgi Geleishvili, Manana Sharashidze, Ketevan Abdushelishvili, Nana Zavradashvili, Jana (Darejan) Javakhishvili; Hungary: Judit Harangozó and Tamás Kurimay; Kosovo: Besnik Stuja, Ferid Agani, Shukrije Statovci; Latvia: Elmars Terauds and Elmars Rancans; Macedonia: Dimitar Bonevski, Izabela Filov, Marija Raleva, Liljana Ignjatova; Montenegro: Helena Rosandic; Russian Federation: Valery Krasnov, Oleg Limankin, Tatiana Solokhina, Yuri Savenko; Slovakia: Ĺubomíra Izáková; Slovenia: to Peter Pregelj, Vesna Švab, Suzana Oreški, Tilen Recko; Ukraine: Semyon Gluzman, Oleh Romanchuk, Vitaly Klymchuk, Orest Suvalo. We would like to acknowledge also those collaborators who wished to stay anonymous. Additionally, we are grateful to Jane Falconer, the London School of Hygiene and Tropical Medicine information specialist, who helped us to develop our search strategy.

\section{Declaration of interests}

We declare that we have no conflicts of interest.

\section{Authors' contributions}

Petr Winkler and Dzmitry Krupchanka have initiated, planned, designed the study, identified country collaborators, coordinated the study, conducted literature review and prepared the first draft of the paper. Both authors contributed equally. Tessa Roberts participated in designing the study, worked on the literature review, screened literature and extracted data, contributed in writing and proofreading the draft. Lucie Kondratova worked on the literature review, screened literature and extracted data; participated in summarizing expert reports; worked on country profiles and commented on the final draft. Vendula Machů worked on extracting the literature and getting access to full-texts; worked on summarizing data into country profiles. Cyril Höschl helped to identify collaborating experts and contributed to the final version of the manuscript. Norman Sartorius 
contributed to the design of the study; helped to identify experts and collaborators across the region; and contributed to the final draft of the paper. Robert Van Voren helped to put the study into the historical and local context, and contributed into the final draft of the manuscript. Country collaborators (Oleg Aizberg, Istvan Bitter, Arlinda Cerga-Pashoja, Azra Deljkovic, Naim Fanaj, Arunas Germanavicius, Hristo Hinkov, Aram Hovsepyan, Fuad N. Ismayilov, Sladana Strkalj Ivezic, Marek Jarema, Vesna Jordanova, Selma Kukić, Nino Makhashvili, Brigita Novak Šarotar, Oksana Plevachuk, Daria Smirnova, Bogdan Ioan Voinescu, Elena Vrublevskaya) have collected expert reports in theirs countries, conducted grey litarature search in local sources, commented on and validated country profiles and contributed to the final draft of the manuscript. Graham Thornicroft supervised the whole project from the very beginning and helped to make many strategic decisions. 


\section{References}

1. UN. United Nations Regional Groups of Member States. 9 May 20142014. http://www.un.org/depts/DGACM/RegionalGroups.shtml (accessed 16 December 2016).

2. CIA. The World Factbook. 2016. https://www.cia.gov/library/publications/the-worldfactbook/ (accessed 13 December 2016).

3. Voren Rv. Cold War in psychiatry : human factors, secret actors. Amsterdam: Rodopi, 2010.

4. Tomov T, Van Voren R, Keukens R, Puras D. Mental health policy in former eastern bloc countries. Mental Health Policy and Practice Across Europe: The Future Direction of Mental Health Care 2006: 397-426.

5. Tomov T. Mental health reforms in Eastern Europe. Acta Psychiatrica Scandinavica, Supplement 2001; 104: 21-6.

6. Assembly UG. Universal declaration of human rights. UN General Assembly 1948.

7. Declaration of Alma-Ata International Conference on Primary Health Care. Alma-Ata, USSR, 612 September 1978.

8. UN. Principles for the protection of persons with mental illness and the improvement of mental health care. Geneva: United Nations: Office of the United Nations High Commissioner for Human Rights, 1991.

9. UN. Convention on the Rights of Persons with Disabilities. New York: United Nations, 2006.

10. Thornicroft G, Rose D. Mental health in Europe. BMJ 2005; 330: 613-4.

11. World Health Organization ROfES, Academic Search C. Mental Health : Facing the Challenges, Building Solutions: Report from the WHO European Ministerial Conference. 2005.

12. Dlouhy M. Mental health policy in Eastern Europe: a comparative analysis of seven mental health systems. BMC health services research 2014; 14: 42.

13. Whiteford HA, Degenhardt L, Rehm J, et al. Global burden of disease attributable to mental and substance use disorders: findings from the Global Burden of Disease Study 2010. The Lancet 2013; 382(9904): 1575-86.

14. Priebe $\mathrm{S}$, Bogic $\mathrm{M}$, Ajdukovic $\mathrm{D}$, et al. Mental disorders following war in the Balkans a study in 5 countries. Archives of General Psychiatry 2010; 67: 518-28.

15. WHO. Suicide data. 2012 (accessed April 4, 2015 2015).

16. WHO. Global status report on alcohol and health: World Health Organization; 2014.

17. Furedi J, Mohr P, Swingler D, et al. Psychiatry in selected countries of Central and Eastern Europe: An overview of the current situation. Acta Psychiatrica Scandinavica 2006; 114: 223-31.

18. Winkler P, Mlada K, Krupchanka D, Agius M, Ray MK, Hoschl C. Long-term hospitalizations for schizophrenia in the czech republic 1998-2012. Schizophrenia Research 2016; 175(1): 180-185.

19. Saraceno B, Saxena S. Mental health services in Central and Eastern Europe: Current state and continuing concerns. Epidemiologia e Psichiatria Sociale 2005; 14: 44-8.

20. Van Voren R, European P, Directorate-General for External Policies of the U. Psychiatry as a tool for coercion in post-Soviet countries. 2013.

21. Allen S. Coercion and human rights in Czech psychiatry: A human rights perspective from MDAC. The Lancet Psychiatry 2014; 1: 177-8.

22. Mossialos E, Murthy A, McDaid D. European Union enlargement: will mental health be forgotten again? European Journal of Public Health 2003; 13: 2-3.

23. Lokshina T, Sergeeva I, Moskovskaia khel'sinkskaia g, Nezavisimaia psikhiatricheskaia a. Human rights and psychiatry in the Russian Federation : report based on monitoring findings and thematic articles. [Moscow]: Moscow Helsinki Group; 2004.

24. Krupchanka D. Winkler P. State of mental healthcare systems in Eastern Europe: do we really understand what is going on? BJPsych International 2016; 13(4): 96-9.

25. McDaid D, Knapp M, Curran C, et al. Meeting the challenge of funding and allocating resources to mental health across Europe: Developing the Mental Health Economics European Network. Epidemiologia e Psichiatria Sociale 2006; 15: 117-22. 
26. Forsman AK, Ventus DB, van der Feltz-Cornelis CM, Wahlbeck K. Public mental health research in Europe: a systematic mapping for the ROAMER project. European journal of public health 2014; 24(6): 955-60.

27. Evans-Lacko S, Courtin E, Fiorillo A, et al. The state of the art in European research on reducing social exclusion and stigma related to mental health: a systematic mapping of the literature. European Psychiatry 2014; 29(6): 381-9.

28. Levac D, Colquhoun H, O'Brien KK. Scoping studies: advancing the methodology. Implementation Science 2010; 5(1): 1.

29. Tricco AC, Lillie E, Zarin W, et al. A scoping review on the conduct and reporting of scoping reviews. $B M C$ medical research methodology 2016; 16(1): 1.

30. Arksey H, O'Malley L. Scoping studies: towards a methodological framework. International journal of social research methodology 2005; 8(1): 19-32.

31. Armstrong R, Hall BJ, Doyle J, Waters E. 'Scoping the scope' of a cochrane review. Journal of Public Health 2011; 33(1): 147-50.

32. Maj M. Psychiatric research in low- and middle-income countries: The need for concrete action. Acta Psychiatrica Scandinavica 2005; 111: 329-30.

33. Ruggeri M, Leese M, Thornicroft G, Bisoffi G, Tansella M. Definition and prevalence of severe and persistent mental illness. The British Journal of Psychiatry. 2000;177(2): 149-55.

34. Gustavsson A, Svensson M, Jacobi F, et al. Cost of disorders of the brain in Europe 2010. European neuropsychopharmacology: the journal of the European College of Neuropsychopharmacology 2011; 21(10): 718-79.

35. Gale NK, Heath G, Cameron E, Rashid S, Redwood S. Using the framework method for the analysis of qualitative data in multi-disciplinary health research. BMC medical research methodology 2013; 13(1): 117.

36. Reinap M, Lai T, Janno S, Tamme T, Tamm M. Cost-Effectiveness of Mental Health Interventions in Estonia. Talinn, 2005.

37. Tomov T. Mental health reforms in Eastern Europe. Acta Psychiatrica Scandinavica 2001; 104: 21-6.

38. Friedman JR. "A world crazier than us": Vanishing social contexts and the consequences for psychiatric practice in contemporary Romania. Transcultural Psychiatry 2016; 53: 176-97.

39. Hoschl C, Winkler P, Peec O. The state of psychiatry in the Czech Republic. International Review of Psychiatry 2012; 24: 278-85.

40. Carlson P. Self-perceived health in East and West Europe: another European health divide. Social science \& medicine 1998; 46(10): 1355-66.

41. Bitter I. Mental disorders and economic change--the example of Hungary. Bulletin of the World Health Organization 2000; 78(4): 505.

42. Anonymous. Debate on political abuse of psychiatry in Lithuania. Mental Health Reforms 1997; 2: 2-5.

43. Samele C, Frew S, Urquia N. Mental Health Systems in the European Union Member States, Status of Mental Health in Populations and Benefits to be Expected from Investments Into Mental Health: European Profile of Prevention and Promotion of Mental Health (EuroPoPP-MH):[main Report]: European Commision, Executive Agencz for Health and Consumers Tender; 2013.

44. UN. Sustainable Development Goals: 17 goals to transform our world. New York: United Nations: Division for Sustainable Development Department of Economic and Social Affairs, 2016.

45. The World Bank, Organization WH. Out of the Shadows: Making mental health a global development priority. Report of Proceedings of Event. Washington DC: World Bank Group, 2016.

46. WHO. mhGAP Intervention Guide for mental, neurological and substance use disorders in nonspecialized health settings. Geneva: World Health Organization, 2016.

47. Saxena $S$, Funk $M$, Chisholm $D$. World health assembly adopts comprehensive mental health action plan 2013-2020. The Lancet 2013; 381(9882): 1970-1. 
48. WHO. Mental health action plan 2013 - 2020.2013. http://apps.who.int/iris/bitstream/10665/89966/1/9789241506021_eng.pdf?ua=1 (accessed Dec 15, 2016. 
Figures and Tables

Figure 1 PRISMA flowchart

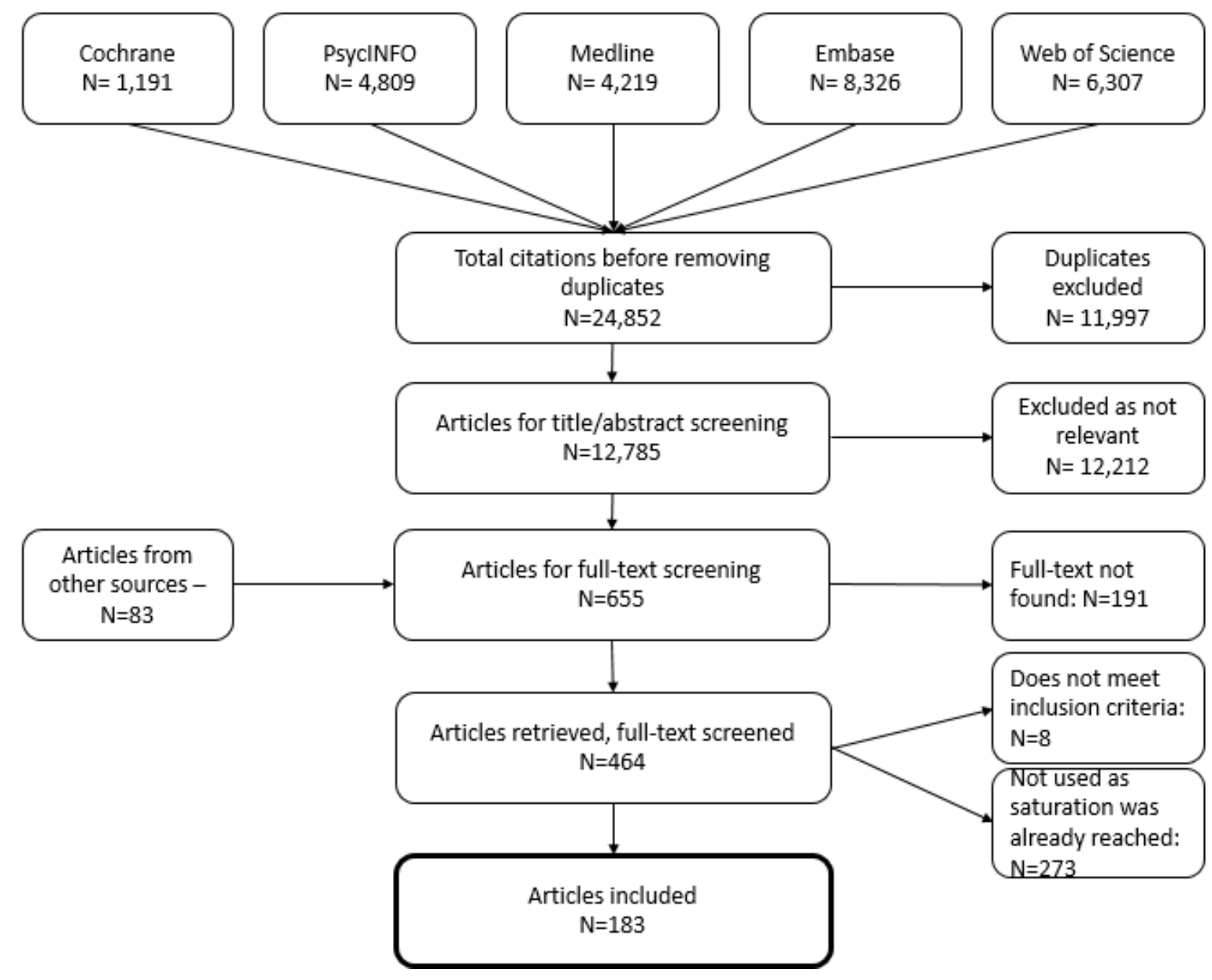


Table 1 Number of papers found, stratified by topic and country of interest. The equivalent table with full references is presented in Appendix 4.

\begin{tabular}{|c|c|c|c|c|c|c|c|c|c|c|}
\hline Region and country / Topic & $\begin{array}{l}\text { Epidemiol } \\
\text { ogy (IF / } \\
\text { no IF) }\end{array}$ & $\begin{array}{l}\text { Services: } \\
\text { structure, } \\
\text { developm } \\
\text { ent, } \\
\text { reforms } \\
\text { (IF / no IF) }\end{array}$ & $\begin{array}{l}\text { Services: } \\
\text { economic } \\
\text { evaluation } \\
\text { (IF / no IF) }\end{array}$ & Resources & $\begin{array}{l}\text { Policy and } \\
\text { legislation }\end{array}$ & $\begin{array}{l}\text { Human } \\
\text { rights }\end{array}$ & $\begin{array}{l}\text { User } \\
\text { Involveme } \\
\text { nt }\end{array}$ & $\begin{array}{l}\text { Education } \\
\text { and } \\
\text { human } \\
\text { resources }\end{array}$ & $\begin{array}{l}\text { Stigma (IF } \\
\text { / no IF) }\end{array}$ & Row Total \\
\hline \multicolumn{11}{|l|}{ Central and Eastern Europe } \\
\hline Czech Rep. & $0 / 4$ & $4 / 10$ & $1 / 0$ & $3 / 1$ & $0 / 3$ & $3 / 2$ & $0 / 0$ & $2 / 0$ & $2 / 2$ & $15 / 22$ \\
\hline Hungary & $1 / 3$ & $4 / 14$ & $0 / 1$ & $0 / 2$ & $1 / 4$ & $0 / 0$ & $0 / 0$ & $0 / 0$ & $1 / 1$ & $8 / 24$ \\
\hline Poland & $5 / 1$ & $14 / 3$ & $2 / 1$ & $2 / 0$ & $5 / 8$ & $1 / 0$ & $1 / 0$ & $3 / 0$ & $8 / 2$ & $41 / 15$ \\
\hline Slovakia & $0 / 1$ & $0 / 4$ & $0 / 0$ & $0 / 0$ & $0 / 0$ & $0 / 0$ & $0 / 0$ & $0 / 0$ & $0 / 0$ & $0 / 5$ \\
\hline \multicolumn{11}{|l|}{ Southeastern Europe } \\
\hline Albania & $1 / 0$ & $1 / 2$ & $0 / 0$ & $0 / 0$ & $0 / 0$ & $0 / 0$ & $0 / 0$ & $0 / 0$ & $0 / 0$ & $2 / 2$ \\
\hline Bos. \& Herc. & $1 / 0$ & $3 / 7$ & $0 / 0$ & $0 / 0$ & $0 / 0$ & $0 / 0$ & $0 / 0$ & $0 / 1$ & $0 / 0$ & $4 / 8$ \\
\hline Bulgaria & $0 / 0$ & $3 / 3$ & $0 / 0$ & $0 / 2$ & $2 / 0$ & $0 / 0$ & $0 / 0$ & $0 / 0$ & $0 / 0$ & $5 / 5$ \\
\hline Croatia & $0 / 1$ & $0 / 11$ & $0 / 0$ & $0 / 0$ & $2 / 5$ & $1 / 0$ & $0 / 0$ & $3 / 2$ & $3 / 3$ & $9 / 22$ \\
\hline Kosovo & $0 / 1$ & $2 / 2$ & $0 / 0$ & $0 / 0$ & $0 / 0$ & $0 / 0$ & $0 / 0$ & $0 / 0$ & $0 / 1$ & $2 / 4$ \\
\hline Macedonia & $0 / 0$ & $0 / 2$ & $0 / 0$ & $0 / 0$ & $1 / 1$ & $0 / 0$ & $0 / 0$ & $0 / 0$ & $0 / 0$ & $1 / 3$ \\
\hline Moldova & $0 / 1$ & $0 / 5$ & $0 / 0$ & $0 / 0$ & $0 / 0$ & $0 / 0$ & $0 / 0$ & $0 / 0$ & $0 / 0$ & $-/ 6$ \\
\hline Montenegro & $0 / 0$ & $0 / 1$ & $0 / 0$ & $0 / 0$ & $0 / 1$ & $0 / 0$ & $0 / 0$ & $0 / 0$ & $0 / 0$ & $-/ 2$ \\
\hline Serbia & $0 / 0$ & $2 / 1$ & $0 / 0$ & $0 / 0$ & $0 / 3$ & $0 / 0$ & $0 / 0$ & $0 / 1$ & $4 / 0$ & $6 / 5$ \\
\hline Slovenia & $0 / 0$ & $9 / 2$ & $0 / 1$ & $0 / 0$ & $1 / 0$ & $0 / 1$ & $0 / 0$ & $1 / 0$ & $0 / 1$ & $11 / 5$ \\
\hline Romania & $0 / 2$ & $4 / 3$ & $0 / 0$ & $0 / 0$ & $1 / 1$ & $1 / 0$ & $1 / 0$ & $0 / 1$ & $0 / 0$ & $8 / 6$ \\
\hline \multicolumn{11}{|l|}{ Baltic } \\
\hline Estonia & $0 / 0$ & $4 / 4$ & $0 / 1$ & $0 / 0$ & $0 / 0$ & $0 / 0$ & $0 / 0$ & $0 / 0$ & $0 / 0$ & $4 / 5$ \\
\hline Latvia & $1 / 0$ & $3 / 1$ & $0 / 0$ & $0 / 0$ & $0 / 0$ & $0 / 0$ & $0 / 0$ & $0 / 0$ & $2 / 0$ & $6 / 1$ \\
\hline Lithuania & $0 / 0$ & $2 / 6$ & $0 / 1$ & $0 / 0$ & $0 / 0$ & $0 / 1$ & $0 / 1$ & $0 / 0$ & $1 / 3$ & $3 / 12$ \\
\hline \multicolumn{11}{|c|}{ Eastern Europe, Russia, Caucasus } \\
\hline Armenia & $0 / 0$ & $0 / 5$ & $0 / 0$ & $0 / 0$ & $0 / 0$ & $0 / 0$ & $0 / 0$ & $0 / 0$ & $0 / 0$ & $0 / 5$ \\
\hline Azerbaijan & $0 / 0$ & $0 / 4$ & $0 / 0$ & $0 / 0$ & $0 / 0$ & $0 / 0$ & $0 / 0$ & $0 / 0$ & $0 / 0$ & $0 / 4$ \\
\hline Belarus & $0 / 1$ & $0 / 4$ & $0 / 0$ & $0 / 0$ & $0 / 2$ & $0 / 1$ & $0 / 0$ & $0 / 0$ & $1 / 0$ & $1 / 7$ \\
\hline Georgia & $1 / 1$ & $1 / 0$ & $0 / 0$ & $0 / 0$ & $0 / 0$ & $0 / 0$ & $0 / 0$ & $0 / 0$ & $0 / 0$ & $4 / 1$ \\
\hline Russia & $2 / 7$ & $12 / 41$ & $1 / 3$ & $1 / 6$ & $4 / 2$ & $1 / 3$ & $0 / 2$ & $1 / 1$ & $4 / 6$ & $26 / 70$ \\
\hline Ukraine & $1 / 0$ & $3 / 5$ & $0 / 0$ & $0 / 0$ & $0 / 3$ & $0 / 0$ & $0 / 0$ & $0 / 1$ & $0 / 0$ & $4 / 9$ \\
\hline International & $1 / 0$ & $15 / 10$ & $1 / 0$ & $3 / 1$ & $2 / 0$ & $0 / 3$ & $0 / 2$ & $5 / 2$ & $4 / 1$ & $31 / 19$ \\
\hline Total $\mathrm{N}=458$ & $14 / 23$ & $86 / 150$ & $5 / 8$ & $9 / 12$ & $19 / 33$ & $7 / 11$ & $2 / 5$ & $15 / 9$ & $30 / 20$ & $187 / 271$ \\
\hline
\end{tabular}

